Article

\title{
Air Quality of Beijing and Impacts of the New Ambient Air Quality Standard
}

\author{
Wei Chen ${ }^{1,2, *}$, Fusheng Wang ${ }^{1}$, Guofeng Xiao ${ }^{1}$, Kai Wu ${ }^{1}$ and Shixuan Zhang ${ }^{1}$
}

1 College of Geoscience and Surveying Engineering, China University of Mining and Technology (Beijing), D11 Xueyuan Road, Beijing 100083, China; E-Mails: fusheng_wang1@126.com (F.W.); 13683177203@163.com (G.X.); scwukai1@163.com (K.W.); shixuan_zhang@126.com (S.Z.)

2 Beijing Key Lab of Spatial Information Integration and Applications, Peking University, No. 5 Yiheyuan Road, Beijing 100871, China

* Author to whom correspondence should be addressed; E-Mail: chenw@cumtb.edu.cn; Tel.: +86-138-119-50643.

Academic Editor: Robert W. Talbot

Received: 19 July 2015 / Accepted: 12 August 2015 / Published: 20 August 2015

\begin{abstract}
Beijing has been publishing daily reports on its air quality since 2000, and while the air pollution index (API) shows that the air quality has improved greatly since 2000, this is not the perception of Beijing's residents. The new national ambient air quality standard (NAAQS-2012), which includes the monitoring of $\mathrm{PM}_{2.5}$, has posed stricter standards for evaluating air quality. With the new national standard, the air quality in Beijing is calculated using both NAAQS-2012 and the previous standard. The annual attainment rate has dropped from $75.5 \%$ to $50.7 \%$. The spatial analysis of air quality shows that only a background station could attain the national standard, while urban and suburban stations exceed the national standard. Among the six pollutants included in the NAAQS-2012, PM2.5 is the major contributor to the air quality index (AQI) comparing with the five other pollutants. The results indicate that under previous NAAQS without $\mathrm{PM}_{2.5}$ monitoring, the air quality has improved greatly in the past decade. By considering $\mathrm{PM}_{2.5}$, the air quality attainment has dropped greatly. Furthermore, a great effort is needed for local government to bring down the $\mathrm{PM} 2.5$ concentration.
\end{abstract}

Keywords: air quality; air pollution; $\mathrm{PM}_{2.5} ; \mathrm{PM}_{10}$ 


\section{Introduction}

Air pollution has become a major concern for residents living in Beijing. Among the major air pollutants are particulate matter (PM), sulphur dioxide, nitrogen oxides, and carbon monoxide. PM is composed of various chemical components, and can profoundly affect people's living environment in terms of air quality and visibility $[1,2]$. $\mathrm{PM}_{10}$ are particles with aerodynamic diameters less than or equal to $10 \mu \mathrm{m}$, consisting mainly of smoke, road dust, and pollen. $\mathrm{PM}_{2.5}$ are particles with aerodynamic diameters less than or equal to $2.5 \mu \mathrm{m}$, and are more likely to be linked to respiratory diseases than PM10. Numerous studies have demonstrated that long-term or even short-term exposure to ambient air with high PM concentrations, especially high $\mathrm{PM}_{2.5}$ concentrations, can increase the risk of morbidity and mortality [3-9]. For example, in China, fine particulate matter is believed to affect the health of adults and children [10], and long-term exposure to both $\mathrm{PM}_{2.5}$ and $\mathrm{PM}_{10}$ has adverse effects on human health [11]. Moreover, many diseases such as atopic asthma, cardiovascular disease, and sudden mortality could be associated with the increase of particulate matter in ambient air [12,13].

Beijing, the capital of China, has a population of more than 19 million [14], and has experienced rapid economic development over the past three decades. During this period, the total number of vehicles has increased rapidly, releasing exhaust pollution to the urban atmosphere [15]. At the same time, the population increase has increased coal energy consumption in Beijing, where coal is the main energy source, especially for heating in winter [16]. Along with the rapid development in the economy and of energy consumption, the air quality in this city has begun to attract public attention. Air pollution in Beijing has been found to vary with seasons and months, reflecting weather conditions and human activity. During the haze-fog period, the chemical components of air pollution in Beijing are deeply affected by nearby cities [17]. Seasonal variations are also found in air pollution in the city [1]. Biomass, including wheat straw burning, is also associated with air pollution in Beijing [18,19]. In other words, air pollution in Beijing is affected by local weather and regional air pollution other than local factors, which makes it difficult to manage the air quality in the city. It is also necessary to analyse air quality variations during past years to systematically characterize the annual, seasonal, and monthly patterns of air quality in Beijing [20]. However, current research on the variations in air quality mainly focus on data within one or two years, with little attention paid to long-term variations [21-25].

In the February of 1998, weekly air quality reports became available to the public in Beijing, taking into account Total Suspended Particles (TSP), nitrogen oxides, and sulphur dioxide. On 5 June 2000, Beijing began to report its daily air quality publicly at the request of the former State Environmental Protection Agency of China (now the Ministry of Environmental Protection of China) on its official website (http://www.bjmemc.com.cn/), providing the daily air pollution index and information on primary pollutants when the Air Pollution Index (API) was larger than 50 according to the National Ambient Air Quality Standard (NAAQS-1996). The monitored pollutants have now been changed to $\mathrm{PM}_{10}$, nitrogen dioxide, and sulphur dioxide. This daily report provides a unique way to investigate the variation in air quality in Beijing over the past decade. However, $\mathrm{PM}_{2.5}$, carbon monoxide, and ozone were not included in China's national air quality monitoring until January 2013. Therefore, the API was used to analysis changes in Beijing's air quality from 5 June 2000 to 14 January 2013. From 18 January 2013, according to the new National Ambient Air Quality Standard (NAAQS-2012) released by the Ministry of Environmental Protection of China, Beijing began reporting hourly air quality data, including the Air 
Quality Index (AQI, replacing API), and concentrations of PM2.5, PM10, ozone, sulphur dioxide, nitrogen dioxide, and carbon monoxide.

In this study, we collected daily API data for Beijing from 5 June 2000 to 14 January 2013 and hourly AQI data for Beijing from 18 January 2013 to 31 December 2013. There was a three-day break in the data, from 15 January to 18 January. Daily averaged API values after 18 January were recalculated from hourly pollutant monitoring data from Beijing urban monitoring stations to obtain the full range of API from 2001 to 2013. A comparison of air quality under NAAQS-1996 and NAAQS-2012 is demonstrated in this study with air quality monitoring data in 2013. Furthermore, the spatial distribution of each pollutant and AQI at each station is also analysed.

\section{Data and Methods}

\subsection{Data}

Daily API data were collected from 5 June 2000 to 14 January 2013 at the data center of the Ministry of Environment Protection of China (http://datacenter.mep.gov.cn/report/air_daily/air_dairy.jsp). Data from a total of 86 cities were publicized on this website and can be downloaded freely, including data from Beijing at the very beginning. In total, there are 10 years of daily API report data. For this period, $\mathrm{PM}_{10}$, sulphur dioxide, and nitrogen dioxide were included in the calculation of API. The API of each pollutant mentioned above is calculated following Equation (1):

$$
I A P I_{P}=\frac{I A P I_{H i}-I A P I_{L o}}{B P_{H i}-B P_{L o}}\left(C_{P}-B P_{L o}\right)+I A P I_{L o}
$$

where $L A P I_{p}$ is the individual air pollution index for pollutant $P, C_{p}$ is the concentration of pollutant $P$, $B P_{H i}$ and $B P_{L o}$ are the nearby high and low values of $C_{p}$ shown in Table 1, and $L A P I_{H i}$ and $L A P I_{L o}$ are the individual air pollution indexes in terms of $B P_{H i}$ and $B P_{L o}$ shown in Table 1. After obtaining individual air pollution indexes for $\mathrm{PM}_{10}$, sulfur dioxide, and nitrogen dioxide, the API is calculated using Equation (2). When the API is greater than 50, the pollutant with the largest individual air pollution index is denoted as the primary pollutant. When the API is less than 50, no primary pollutant is reported in the daily report.

$$
A P I=\max \left(I A P I_{\mathrm{PM} 10}, I A P I_{\mathrm{SO}_{2}}, I A P I_{\mathrm{NO}_{2}}\right)
$$

Table 1. Individual air pollution indexes and their corresponding concentration limits.

\begin{tabular}{cccc}
\hline IAPI & $\begin{array}{c}\text { Daily } \mathbf{S O}_{2} \\
\text { Concentration }\end{array}$ & $\begin{array}{c}\text { Daily } \mathbf{N O}_{2} \\
\text { Concentration }\end{array}$ & $\begin{array}{c}\text { Daily } \mathbf{P M}_{\mathbf{1 0}} \\
\text { Concentration }\end{array}$ \\
\hline 50 & 50 & 80 & 50 \\
100 & 150 & 120 & 150 \\
200 & 800 & 280 & 350 \\
300 & 1600 & 565 & 420 \\
400 & 2100 & 750 & 400 \\
500 & 2620 & 940 & 600 \\
\hline
\end{tabular}

In NAAQS-1996, an API value less than or equal to 50 indicates attainment of the Grade I standard. API values falling in the range 50-100, 100-200, 200-300, and larger than 300 are called Grade II, 
Grade III, Grade IV, and Grade V standards, respectively. A daily averaged API less than or equal to 100 (Grade I and Grade II standards) indicates attainment of the national air quality standard, and is called a "Blue Sky" day. From 1998, Beijing launched a "Defending Blue Sky" campaign to report the "Blue Sky Index", describing the number of "Blue Sky" days in Beijing. In that period, there were only 100 "Blue Sky" days in Beijing. In 2012, the Beijing Municipal Environmental Protection Bureau released the number of "Blue Sky" days in Beijing for the last time, demonstrating that the number of "Blue Sky" days had increased to 286, which is contrary to the public awareness that citizens in Beijing are suffering from terrible air quality. In February 2012, the Ministry of Environment Protection of China released the new NAAQS (NAAQS-2012), adopting new air quality monitoring and calculation methods. In January 2013, Beijing launched a new monitoring system and adopted stricter evaluation standards. Under the new NAAQS of China, besides PM10, sulphur dioxide, nitrogen dioxide, $\mathrm{PM}_{2.5}$, ozone, and carbon monoxide are all included in the air quality standard. The index describing air quality is called the AQI and can be calculated similarly to the API following Equation (3):

$$
I A Q I_{P}=\frac{I A Q I_{H i}-I A Q I_{L o}}{B P_{H i}-B P_{L o}}\left(C_{P}-B P_{L o}\right)+I A Q I_{L o}
$$

where $I A Q I_{p}$ is the individual air pollution index for pollutant $P, C_{p}$ is the concentration of pollutant $P$, and $B H_{H i}$ and $B H_{L o}$ are the nearby high and low values of $C_{p}$ shown in Table 2. The maximum IAQI of the six IAQIs ( $\mathrm{PM}_{2.5}, \mathrm{PM}_{10}, \mathrm{O}_{3}, \mathrm{SO}_{2}, \mathrm{NO}_{2}$ and $\left.\mathrm{CO}\right)$ in one day is selected as the daily AQI, similar to Equation (2). From January 2013, China has publicized both real time air quality data (including real time AQI and concentrations of the six pollutants at one-hour intervals) and daily air quality data from 74 major cities, including Beijing, on its web platform. From 2014, the number of cities publicizing air quality data has increased to 190 . For Beijing, a total of 12 monitoring stations is included on this platform to provide real time monitoring data from Beijing. The distribution of the monitoring stations is shown in Figure 1. In total, there are 12 national air quality monitoring stations in Beijing, among which eight are urban stations (marked red in Figure 1), three are suburban stations located in a suburban town north of Beijing (marked purple in Figure 1) and one background station is deployed at Dingling, far away from human activity (marked green in Figure 1).

Table 2. Individual Air Quality Indexes and Their Corresponding Concentration Limits.

\begin{tabular}{|c|c|c|c|c|c|c|}
\hline IAQI & $\begin{array}{c}\text { Daily } \mathrm{SO}_{2} \\
\text { Concentration } \\
\left(\mu \mathrm{g} / \mathrm{m}^{3}\right) \\
\end{array}$ & $\begin{array}{c}\text { Daily } \mathrm{NO}_{2} \\
\text { Concentration } \\
\left(\mu \mathrm{g} / \mathbf{m}^{3}\right) \\
\end{array}$ & $\begin{array}{c}\text { Daily PM10 } \\
\text { Concentration } \\
\left(\mu \mathrm{g} / \mathbf{m}^{3}\right) \\
\end{array}$ & $\begin{array}{c}\text { Daily CO } \\
\text { Concentration } \\
\left(\mathbf{m g} / \mathbf{m}^{3}\right) \\
\end{array}$ & $\begin{array}{c}\text { Daily } \mathrm{O}_{3} \\
\text { Concentration } \\
\left(\mu \mathrm{g} / \mathbf{m}^{3}\right) \\
\end{array}$ & $\begin{array}{c}\text { Daily } \mathrm{PM}_{2.5} \\
\text { Concentration } \\
\left(\mu \mathrm{g} / \mathbf{m}^{3}\right) \\
\end{array}$ \\
\hline 50 & 50 & 40 & 50 & 2 & 160 & 35 \\
\hline 100 & 150 & 80 & 150 & 4 & 200 & 75 \\
\hline 150 & 475 & 180 & 250 & 14 & 300 & 115 \\
\hline 200 & 800 & 280 & 350 & 24 & 400 & 150 \\
\hline 300 & 1600 & 565 & 420 & 36 & 800 & 250 \\
\hline 400 & 2100 & 750 & 500 & 48 & 1000 & 350 \\
\hline 500 & 2620 & 940 & 600 & 60 & 1200 & 500 \\
\hline
\end{tabular}




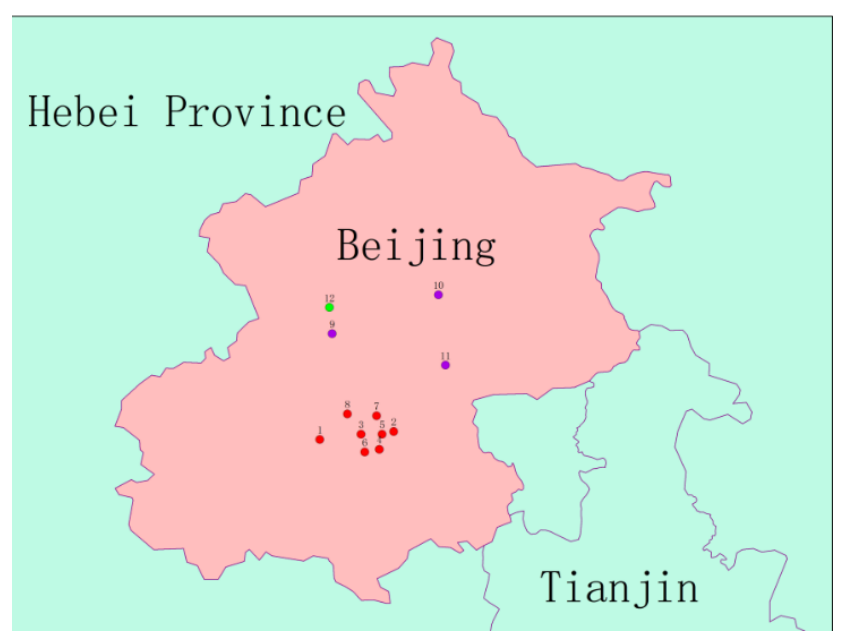

Figure 1. Distribution of National Air Quality Monitoring Stations in Beijing. Red dots are urban stations, and purple dots are suburban stations. Green dot is the background station in Dingling, far away from human activity, providing background value of air quality in Beijing. The 12 stations are: 1, Gucheng; 2, Nongzhanguang; 3, Guanyuan; 4, Tiantan; 5, Dongsi; 6, Wanshouxigong; 7, Aoti; 8, Wanliu; 9, Changping; 10, Huairou; 11, Shunyi; 12, Dingling.

\subsection{Methods}

The annual, seasonal, and monthly API of Beijing from 2000 to 2013 was investigated for the first time in this study. As the API was replaced by the AQI beginning in January 2013, we use the hourly monitoring air quality data to recalculate the API in 2013 for each day using Equations (1) and (2). Among the 12 monitoring stations, the background station in Dingling is not included in the calculation of API because it is little affected by human activity and does not represent the ambient air quality affected by humans.

"Blue Sky" days are an important index for assessing air pollution control performance. It is reported that the number of "Blue Sky" days in Beijing has increased from 185 days in 2001 to 286 days in 2011, after which "Blue Sky" days were removed from the air quality assessment system. By utilizing API daily report data from 2012 and real time monitoring data from 2013, the "Blue Sky" days of 2012 and 2013 are calculated to present the air quality trend. Furthermore, air quality attainment days and air pollution levels for 2001 to 2013 are also investigated. The NAAQS-1996 and NAAQS-2012 are different in the attainment level of air quality. With real time monitoring data of 2013, the air quality attainment days and air quality pollution levels in 2013 under the two NAAQS are also presented and compared to evaluate the new NAAQS impact on air quality assessment. Additionally, the spatial variation of air quality is also included in this study.

\section{Results and Discussion}

\subsection{Air Pollution and Quality under NAAQS-1996}

The annual, seasonal, and monthly API and PM10 of Beijing from 2000 to 2013 are shown in Figures 2 and 3 under NAAQS-1996. The maximum annual API was about 113 in 2001 (because of lack 
of data during the first five months of 2000, the annual API of 2000 was less than that of 2001). The annual API values from 2001 to 2007 decreased slowly above 100, then dropped directly to 80 to 90 levels from 2008. The minimum annual API was about 78 in 2012. In 2013, the annual API had a small increase to 85 . In terms of seasonal variation, the lowest average API of 83 occurred in the summer, followed by autumn, winter, and spring. Spring had the largest average API of 109.

Daily $\mathrm{PM}_{10}$ concentrations are back-calculated for days when $\mathrm{PM}_{10}$ was the primary pollutant, as shown in Figure 3. The annual, seasonal, and monthly $\mathrm{PM}_{10}$ concentration trends are similar to those of the API. The maximum annual PM10 concentration was $175 \mu \mathrm{g} / \mathrm{m}^{3}$ in 2001 , and the minimum annual $\mathrm{PM}_{10}$ content was $109 \mu \mathrm{g} / \mathrm{m}^{3}$ in 2012. Summer had the lowest $\mathrm{PM}_{10}$ concentration of $118 \mu \mathrm{g} / \mathrm{m}^{3}$ followed by autumn, winter, and spring, which was around $170 \mu \mathrm{g} / \mathrm{m}^{3}$. The reason for this may be that most rainfalls (data of rainfalls of Beijing is downloaded from China Meteorological Data Sharing Service System, http://cdc.nmic.cn) in Beijing occur in the summer as shown in Figure 4, and the rain washes away the particulate matter in the atmosphere and particulate matter is the major cause for the air pollution in Beijing. The monthly results further show that July and August have the least pollution, and April has the most pollution.
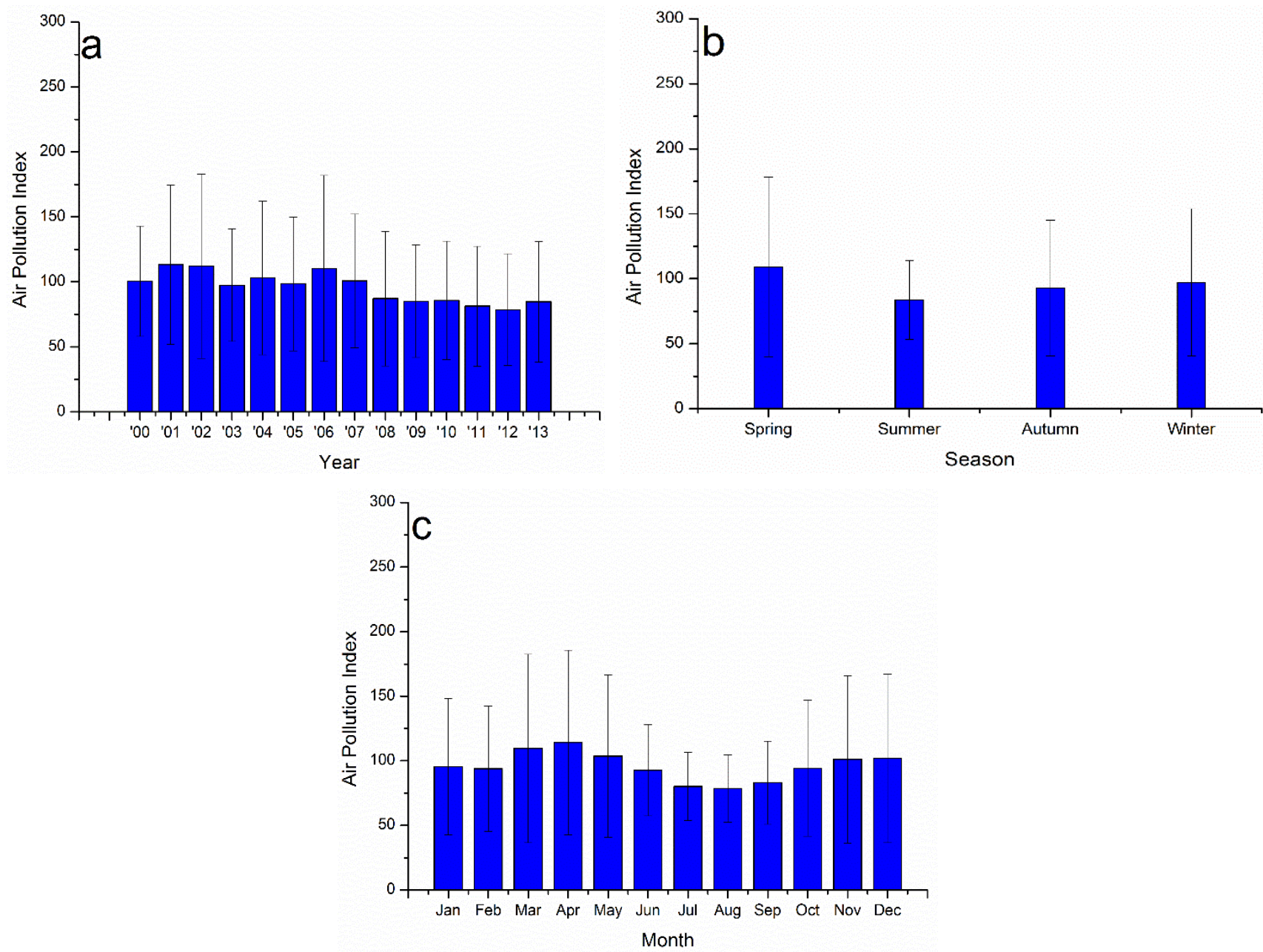

Figure 2. Annual (a), seasonal (b), and monthly (c) Air Pollution Index variations in Beijing in 2001-2013 (The interval limits are the standard deviations). 

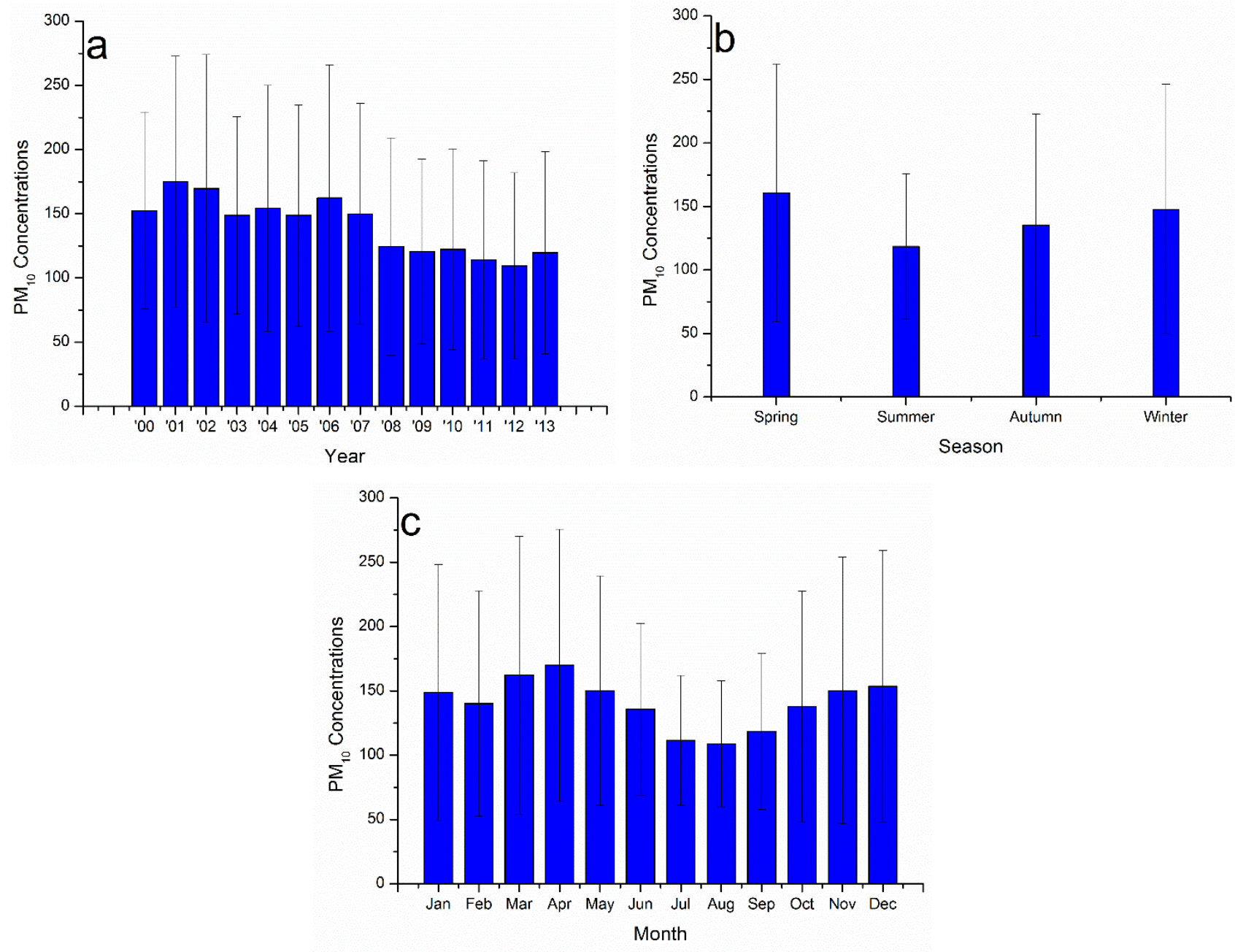

Figure 3. Annual (a), seasonal (b), and monthly (c) $\mathrm{PM}_{10}$ variations in Beijing in 2001 to 2013(The interval limits are the standard deviations).
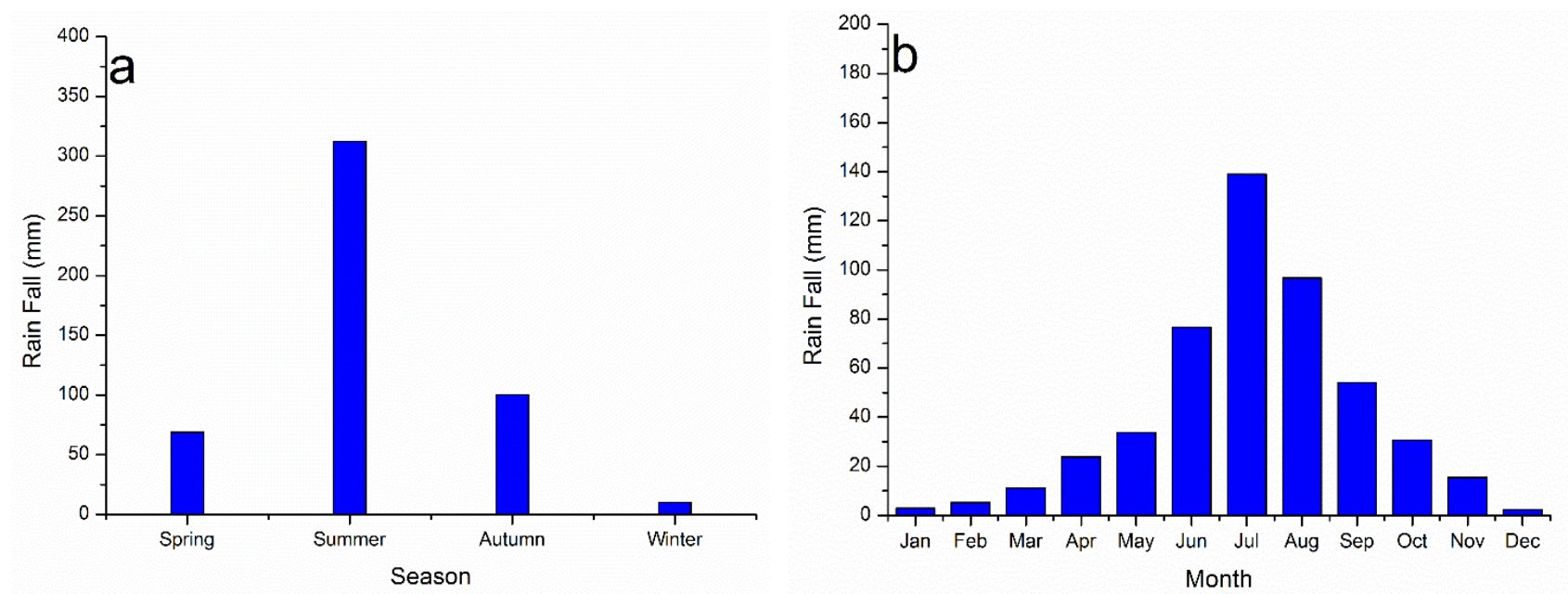

Figure 4. Seasonal (a) and monthly (b) precipitations in Beijing.

In the NAAQS-1996, days with level 1 (API less than or equal to 50) and level $2(50<$ API $\leqslant 100$ ) air quality are called attainment days. Days with air quality falling in the range of level $3(100<\mathrm{API} \leqslant 200)$, $4(200<$ API $\leqslant 300)$, and 5 (API > 300) are non-attainment days. Attainment days are called "Blue Sky" 
days. Table 3 shows the "Blue Sky" days and pollution levels from 2001 to 2013. The "Blue Sky" days increased slowly and steadily, from 185 in 2001 to 286 in 2010. Then, in 2011, the increase stopped, and the number decreased to 281 in 2012 and 271 in 2013 . This indicates that the air quality actually became worse in 2010 after 11 years of improvement. The number of level 1 days increased from 12 in 2001 to 85 in 2012, then decreased sharply to 58 in 2013. This is consistent with the fact that heavy haze occurred frequently in Beijing during the winter of 2013. The number of days with heavy pollution (level 4 and level 5 days) has decreased from 23 in 2001 to less than 10 in 2008. This indicates that after 10 years of air quality control, the air quality in Beijing has experienced some improvement. Under NAAQS-1996, air quality has improved tremendously from 2001 to 2013 [26,27], however, the frequent haze-fog events seem to be inconsistent with the "nominal" improvement of air quality. The reason for this maybe the neglect of the inclusion of $\mathrm{PM}_{2.5}$ as pollutant in the NAAQS-1996 when the $\mathrm{PM}_{10}$ concentration drops but $\mathrm{PM}_{2.5}$ concentration is still high in Beijing. As a result, NAAQS-2012 is proposed by adding PM2.5, $\mathrm{CO}$ and ozone monitoring data from 2013. It is therefore necessary to compare the two versions of NAAQS to better understand the results by adopting different air quality standards to evaluate the real improvement in air quality in the past decade.

Table 3. "Blue Sky" days and attainment days in Beijing.

\begin{tabular}{cccccc}
\hline Year & “Blue Sky” Days & Level 1 Days & Level 2 Days & Level 3 Days & Level 4 and 5 Days \\
\hline 2001 & 185 & 12 & 173 & 157 & 23 \\
2002 & 203 & 22 & 181 & 143 & 19 \\
2003 & 224 & 27 & 197 & 136 & 5 \\
2004 & 228 & 33 & 195 & 121 & 17 \\
2005 & 234 & 36 & 198 & 122 & 24 \\
2006 & 241 & 26 & 215 & 100 & 11 \\
2007 & 246 & 32 & 214 & 108 & 8 \\
2008 & 274 & 62 & 212 & 84 & 5 \\
2009 & 285 & 47 & 238 & 75 & 5 \\
2010 & 286 & 53 & 233 & 73 & 5 \\
2011 & 286 & 76 & 210 & 74 & 7 \\
2012 & 281 & 86 & 196 & 81 & 5 \\
2013 & 271 & 58 & 213 & 84 & \\
\hline
\end{tabular}

\subsection{Spatial Variation and Assessment of Air Quality under NAAQS-2012}

As the air quality data before 2013 is the daily average of all monitoring stations without specific data from each station, the spatial pollution distribution of different monitoring sites is not available for days before 2013. After January 2013, data from the 12 real time monitoring stations are publicized on the web platform at one-hour intervals. Most of the monitoring data have been downloaded, except for a few days when the network system was down.

In this paper, we divided the monitoring stations into three categories: a background station, urban stations, and suburban stations. The distribution Station IDs of these monitoring stations are shown in Figure 1. Background station (Station No. 12) located around the Ming Tombs far away from human activities. Seven urban stations are placed at the main urban regions $150 \mathrm{~m}$ away from the main road. The remaining three suburban stations are placed at suburban counties. Atmospheric pollutions of urban and suburban stations are more likely to be affected by local sources. AQI is the comprehensive index 
for evaluating air quality. From Figure 5, only the background station Dingling has an annual average AQI less than 100, which is the attainment value for the daily report. For urban stations, the annual average AQI are all greater than 120, except for Aoti station, which is 110. Dongsi station (Station No. 5) has the maximum annual average AQI of 160 . For suburban stations, the annual average air quality values are better than those of the urban stations, ranging from 100 to 110 . As the new NAAQS states, an AQI value greater than 100 is considered to be unhealthy. Thus, the annual average air quality at the urban and suburban stations all exceed the national standard. Air qualities of urban stations are systematically larger than those of suburban stations. The annual air quality of the background station with an annual AQI of 96 just meets the new national standard. This result indicates that under the new NAAQS, the air quality in the urban and suburban areas where most residents live is not healthy at all.

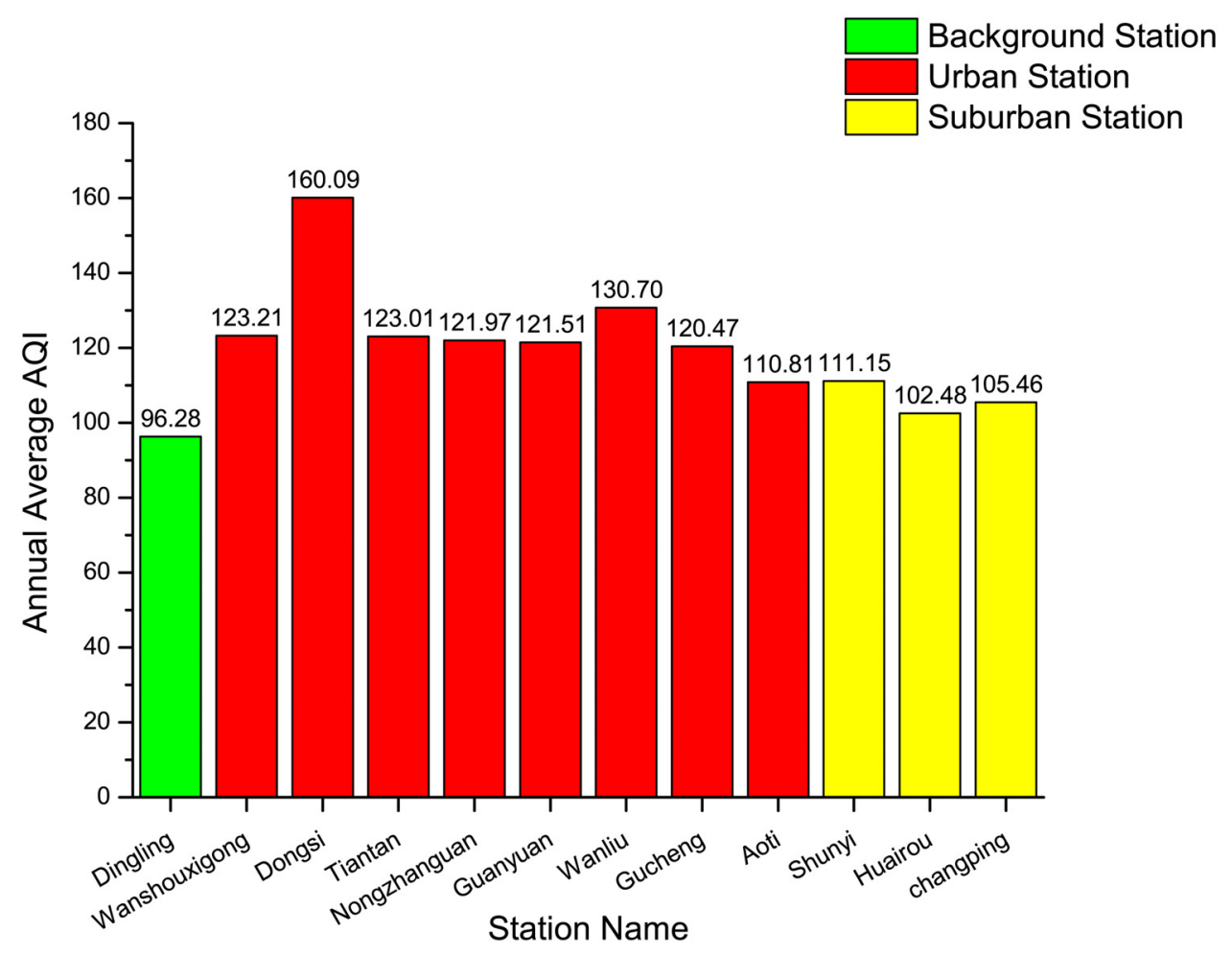

Figure 5. Annual average AQI at each monitoring station.

As shown in Figure 6 the annual average $\mathrm{PM}_{2.5}$ concentration of each monitoring station has a trend similar to that of AQI: the background station has the lowest $\mathrm{PM}_{2.5}$ concentration, and the urban stations have $\mathrm{PM}_{2.5}$ concentrations much greater than that of the suburban and background stations. Dongsi station's (Station No. 5) annual average PM2.5 concentration is the greatest among all the monitoring stations. This indicates that in Beijing, $\mathrm{PM}_{2.5}$ contributes the most to the AQI, and $\mathrm{PM}_{2.5}$ is the primary pollutant under most circumstances. Furthermore, $\mathrm{PM}_{2.5}$ concentrations of urban stations are higher than those of suburban stations except for that of Shunyi Stations. The northern stations (suburban stations), from Figure 6, were less polluted than those southern stations (urban stations), suggesting that there may be some pattern in the spatial distribution of the particulate matter in Beijing. The new NAAQS defines that a daily average $\mathrm{PM}_{2.5}$ concentration greater than $75 \mu \mathrm{g} / \mathrm{m}^{3}$ is not healthy. Under this standard, only the background station and Huairou station (Station No. 10) in the suburbs meet this standard. If the 
World Health Organization (WHO) standard with an annual $\mathrm{PM}_{2.5}$ concentration less than $35 \mu \mathrm{g} / \mathrm{m}^{3}$ is adopted, none of the monitoring stations in Beijing would be able to attain that standard.

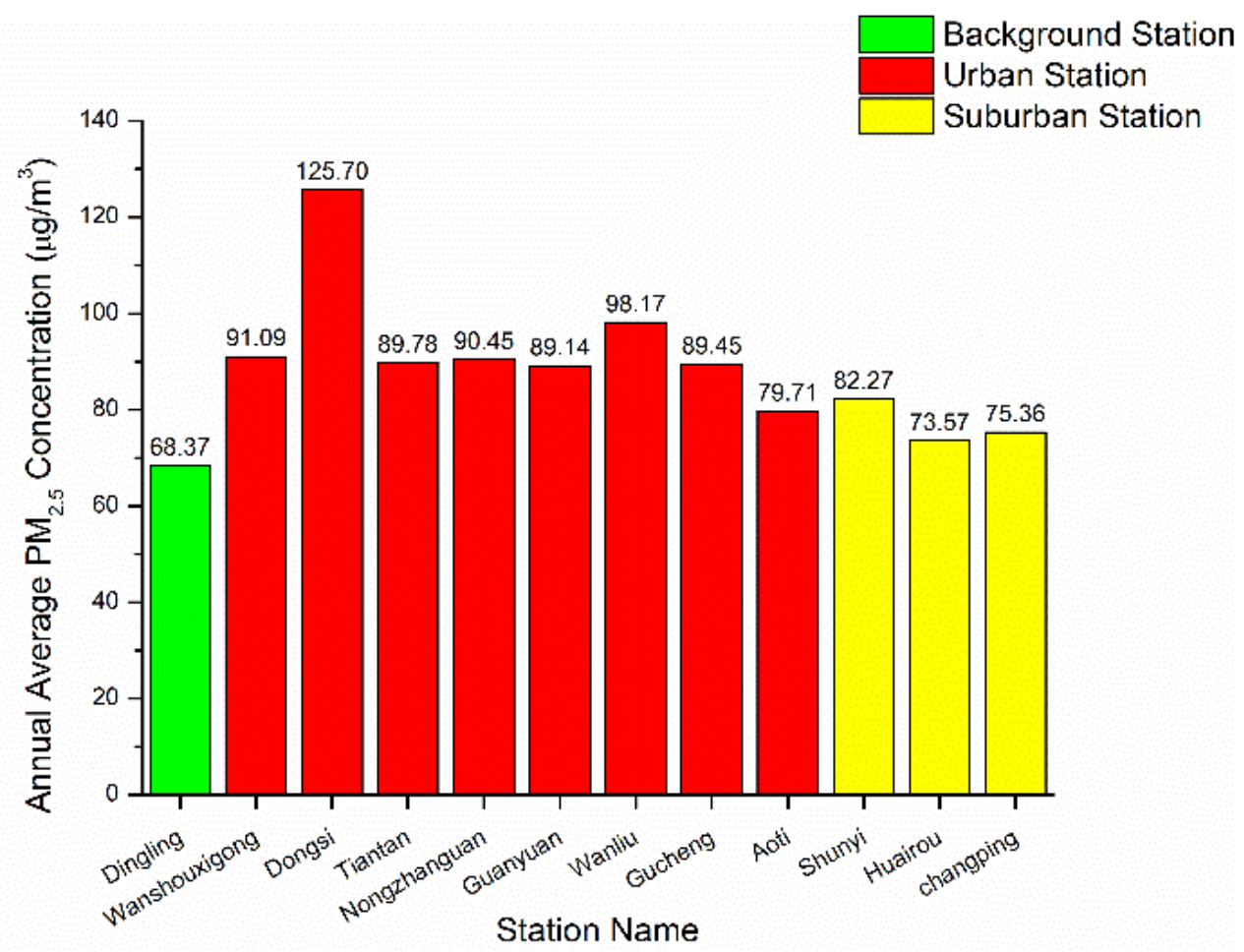

Figure 6. Annual average $\mathrm{PM}_{2.5}$ concentration at each monitoring station.

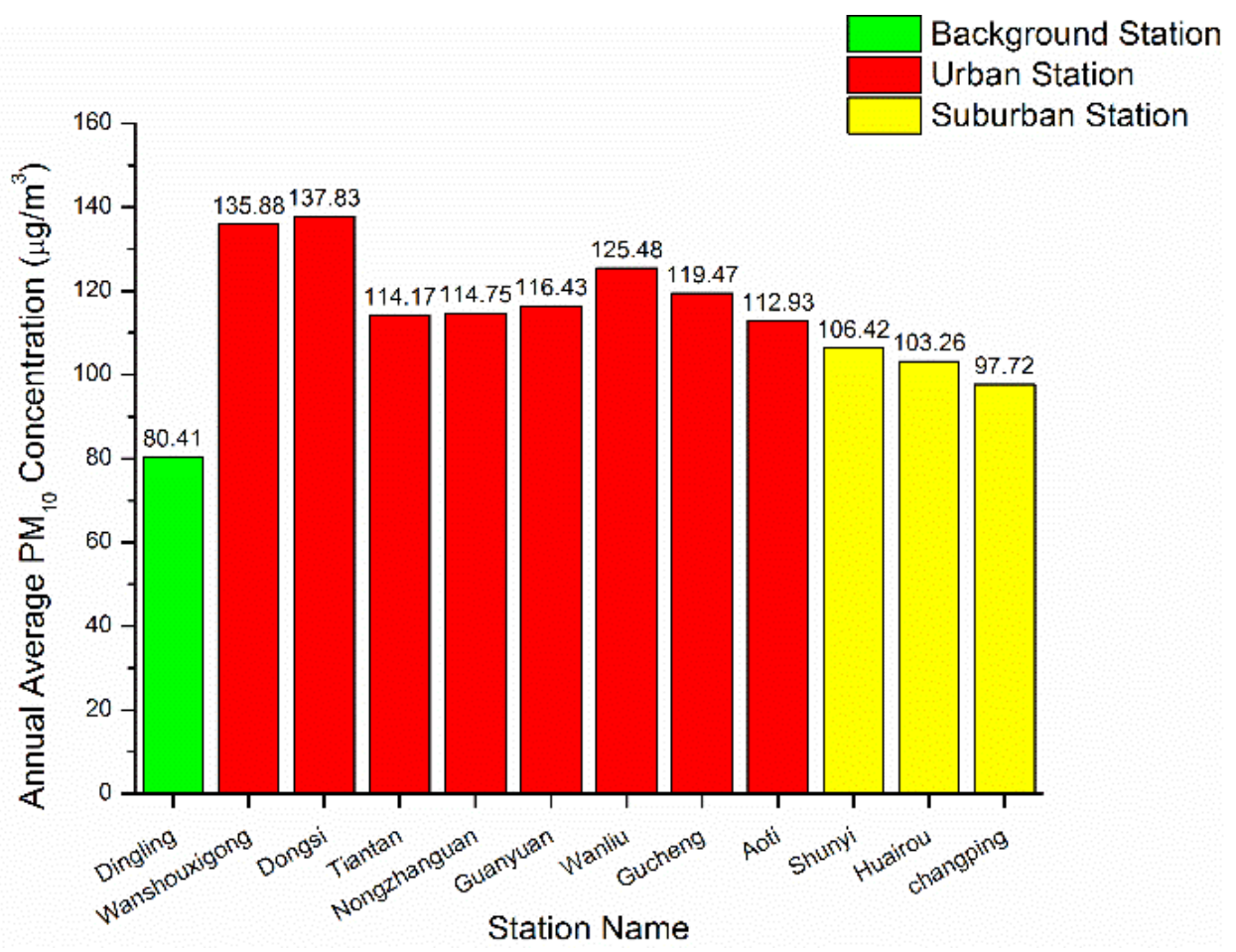

Figure 7. Annual average $\mathrm{PM}_{10}$ concentration at each monitoring station.

For $\mathrm{PM}_{10}$ concentrations (shown in Figure 7), the annual average concentrations at the urban stations are also the largest compared with those at the background station and suburban stations. The annual 
average $\mathrm{PM}_{10}$ concentrations at the urban stations are all greater than $110 \mu \mathrm{g} / \mathrm{m}^{3}$, while the annual average $\mathrm{PM}_{10}$ concentrations at suburban stations are around $100 \mu \mathrm{g} / \mathrm{m}^{3}$. The pattern of spatial distribution of $\mathrm{PM}_{10}$ concentration is similar to that of $\mathrm{PM}_{2.5}$, except at Wanshouxigong station (Station No. 6). This indicates that the ratio of $\mathrm{PM}_{2.5} / \mathrm{PM}_{10}$ is different at different stations, even within a small area. The new NAAQS has not changed the standard for PM10. A daily average PM10 concentration exceeding $150 \mu \mathrm{g} / \mathrm{m}^{3}$ is considered to be unhealthy. In this case, all the monitoring stations' annual average $\mathrm{PM}_{10}$ concentrations are less than $150 \mu \mathrm{g} / \mathrm{m}^{3}$, with a maximum concentration of $137 \mu \mathrm{g} / \mathrm{m}^{3}$ at Dongsi station (Station No. 5). This result is consistent with the improved API under NAAQS-1996, as air quality is "really improving" only when considering $\mathrm{PM}_{10}$ without $\mathrm{PM}_{2.5}$. This result also shows that a great effort is needed for Beijing to satisfy the new standard.

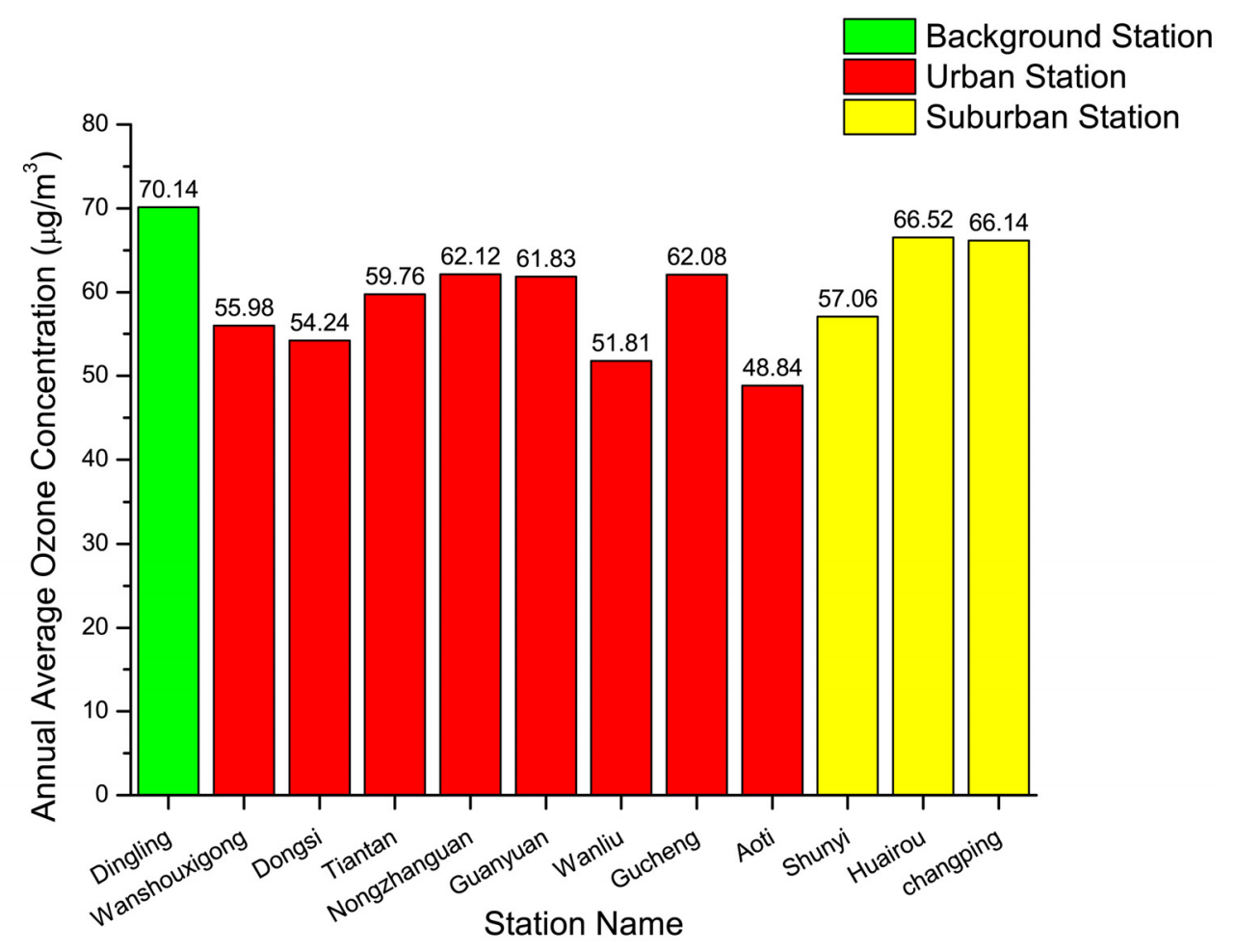

Figure 8. Annual average ozone concentration at each monitoring station.

The pattern of ozone (shown in Figure 8) is completely different from the pattern of $\mathrm{PM}_{2.5}$ and $\mathrm{PM}_{10}$. The background station has the largest annual average concentration of around $70 \mu \mathrm{g} / \mathrm{m}^{3}$, followed by suburban stations ( 57 to $70 \mu \mathrm{g} / \mathrm{m}^{3}$ ) and urban stations. Ozone in the atmosphere is more likely to undergo a chemical reaction with other pollutants such as $\mathrm{NO}_{2}$, a kind of automobile exhaust. Therefore, the low concentrations of ozone in urban and suburban stations maybe caused by the effect of vehicle exhausts. However, the urban stations' annual average concentrations are the lowest. As the ozone contribution to the AQI is less than that of $\mathrm{PM}_{2.5}$ and $\mathrm{PM}_{10}$, this phenomenon is not reflected in the AQI. For sulfur dioxide and nitrogen dioxide (shown in Figures 9 and 10, the spatial distributions are similar to that of the AQI. Dongsi station (Station No. 5) has the largest annual average sulfur dioxide and nitrogen dioxide concentrations among all the monitoring stations. For carbon monoxide (shown in Figure 11), urban station Dongsi (Station No. 5) has the largest annual average concentration of nearly $2.5 \mathrm{mg} / \mathrm{m}^{3}$. The other urban and suburban stations' annual average carbon monoxide concentrations are comparable, 
in the range of 1.2 to $1.5 \mathrm{mg} / \mathrm{m}^{3}$. The nitrogen dioxide concentrations of urban stations are far greater than those of suburban stations. Considering that the nitrogen dioxide is mainly from vehicle exhaust, the high nitrogen dioxide of urban stations may be caused by a large amount of traffic flows. Annual average ozone, sulfur dioxide, nitrogen dioxide, and carbon monoxide concentrations at all the monitoring stations could attain the new national standard (IAQI less than 100). These results show that $\mathrm{PM}_{2.5}$ is the major contributor to the AQI.

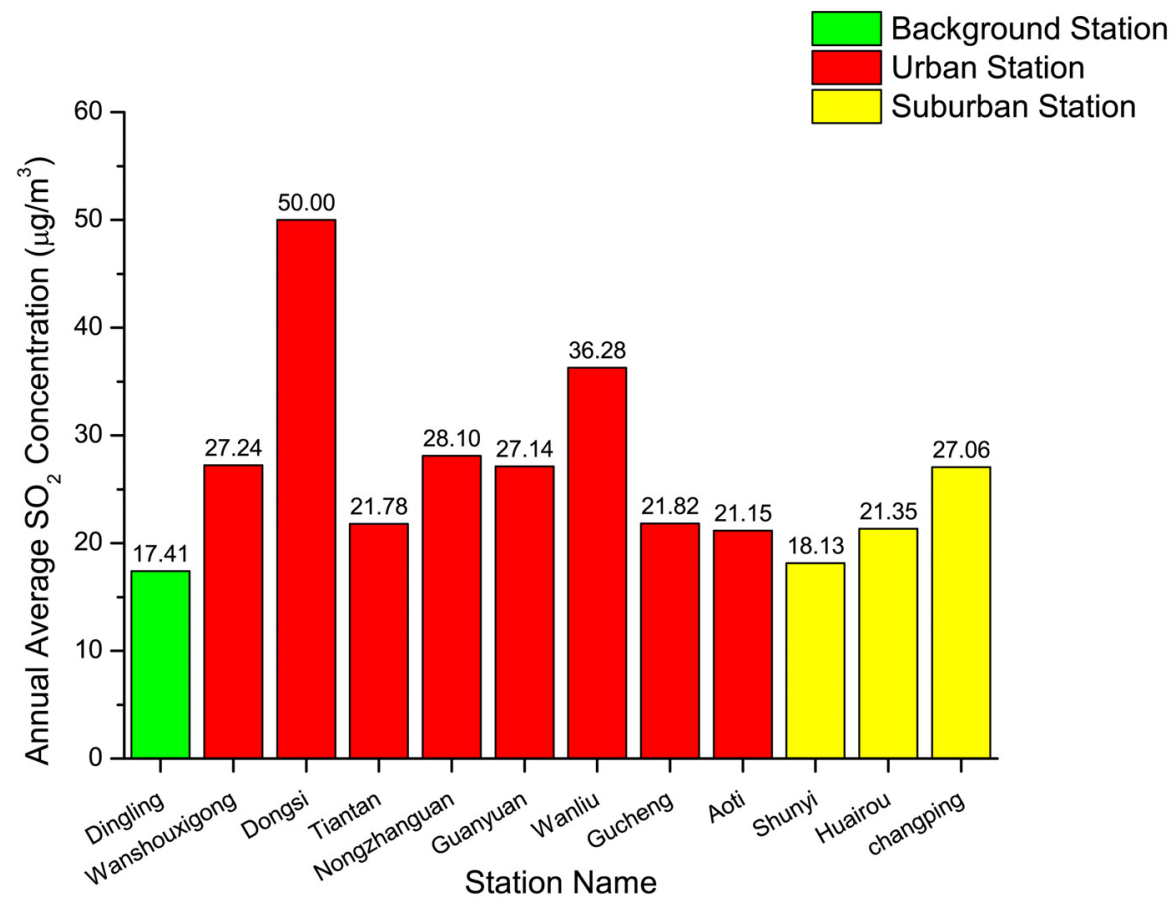

Figure 9. Annual average $\mathrm{SO}_{2}$ concentration at each monitoring station.

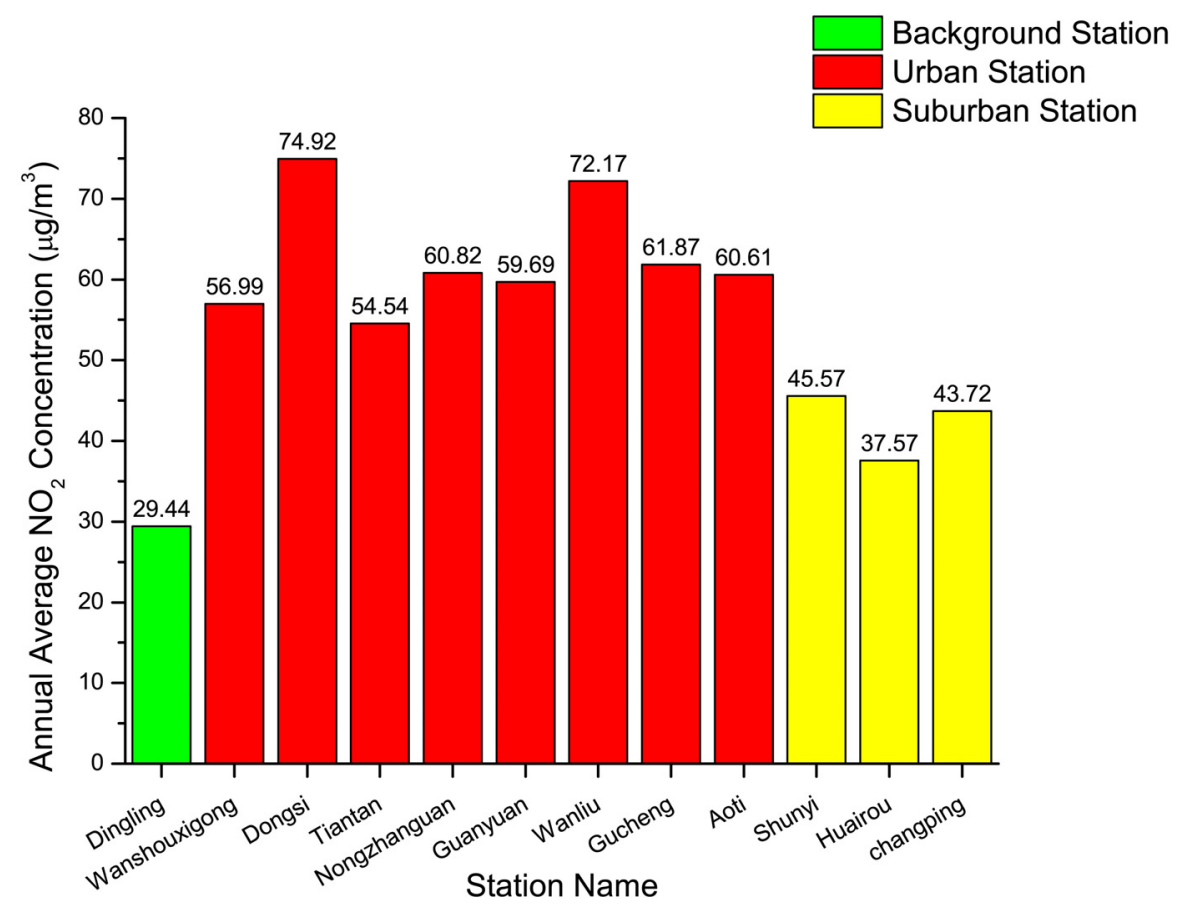

Figure 10. Annual average $\mathrm{NO}_{2}$ concentration at each monitoring station. 


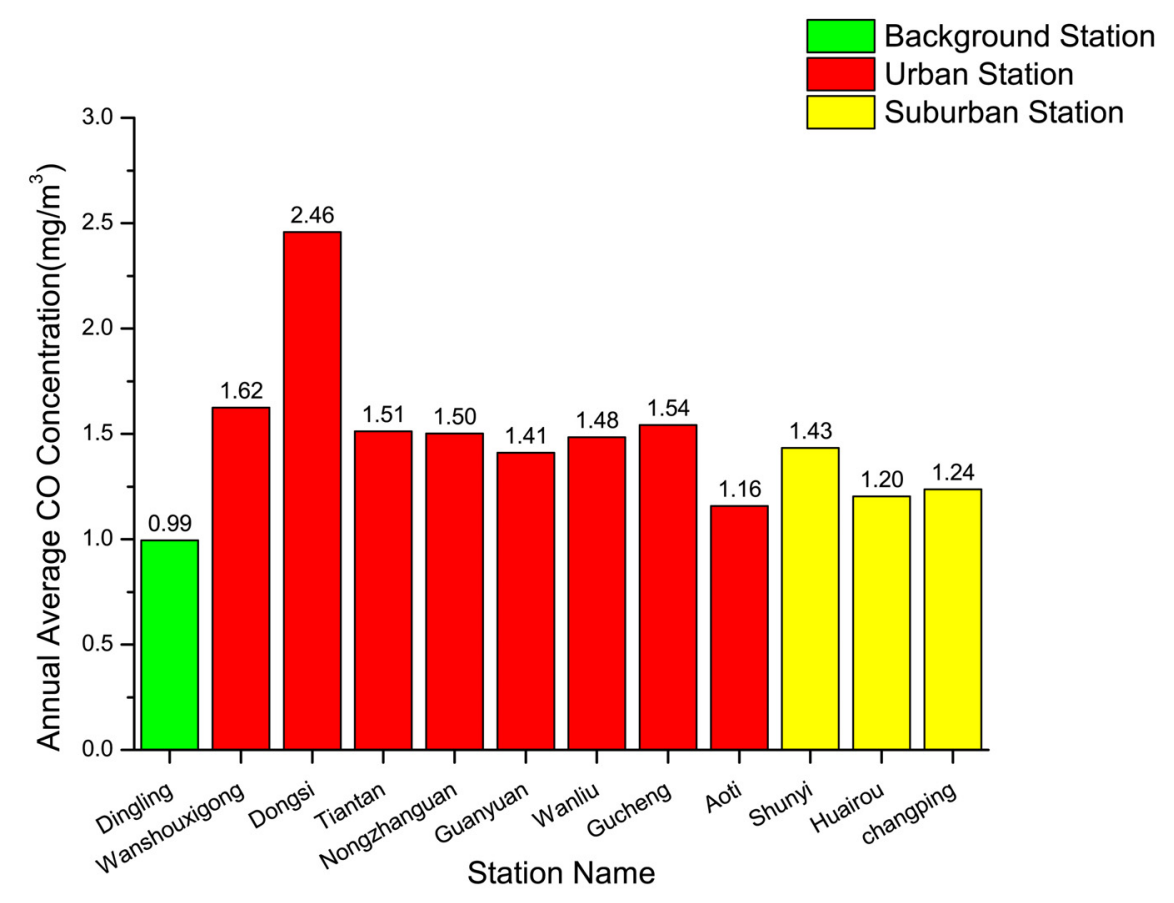

Figure 11. Annual average $\mathrm{CO}$ concentration at each monitoring station.

\subsection{Air Quality Assessment Comparison between Two Versions of NAAQS}

The new NAAQS released in 2012 will greatly bring down the air quality attainment rate in Beijing by introducing restrictions on $\mathrm{PM}_{2.5}, \mathrm{CO}$, and ozone. This fact is known to the local and central governments, and the new NAAQS is facing great opposition from local governments, who are less concerned with this issue. However, pressure from the public has forced local governments to compromise. Here, we simply present a comparison of the air quality assessments between two versions of NAAQS. Under NAAQS-1996, the number of air quality attainment days was 262 (18 January to 31 December, 2013, 347 days in total). The attainment rate is $75.5 \%$ under the NAAQS-1996. The numbers of days attaining level 1,2,3, and worse than 3 are 54, 208, 80, and 5, respectively. That is to say, the number of days attaining the level 2 standard is greater under NAAQS-1996. Additionally, under NAAQS-1996, there are only five days with air quality worse than the level 3 standard. However, under NAAQS-2012, the number of attainment days decreased sharply to 176 , a reduction of nearly $25 \%$. The attainment rate is $50.7 \%$ under the new NAAQS. The number of days attaining levels 1, 2, 3, and worse than 3 are 31, 145, 76, and 96, respectively. These are reductions of $24(44.4 \%)$ and $63(30.3 \%)$ for level 1 and level 2 days, respectively. The number of unhealthy days with air quality worse than the level 3 standard, on the other hand, increased from 5 to 96. In sum, the new NAAQS decreased the number of attainment days significantly, and sharply increased the number of unhealthy days and extremely unhealthy days. This indicates that under the new NAAQS, the number of days with bad air quality increased sharply, posing a difficult problem to the efforts by local governments to control air pollution.

\section{Conclusions}

Air pollution is a major concern for the residents of Beijing. According to the API under NAAQS-1996 for China monitoring of $\mathrm{PM}_{10}$, sulfur dioxide, and nitrogen dioxide, the air quality in Beijing improved 
in 2007 and has since attained the national standard. The "Blue Sky" days with an API less than or equal to 100 has increased from 185 in 2001 to 271 in 2013 . However, this result is different from that perceived by residents. By employing NAAQS-2012 from January 2013, we are able to compare the two versions of NAAQS. By adopting the new NAAQS, the annual attainment drops from $75.5 \%$ to $50.7 \%$. This result suggests that although the official attainment days indicate an improvement of air quality in Beijing as a whole, the real reason is highly likely that $\mathrm{PM}_{2.5}$ concentration was not included in the NAAQS-1996 standard. With the NAAQS-2012, the air quality in Beijing in 2013 drops sharply to around 50\%. Thus, the official improvement announced is thus caused by inadequate air quality standards and the NAAQS-1996 standard may be problematic in evaluating the real air quality compared with NAAQS-2012. Furthermore, NAAQS-2012 poses a difficult challenge for local governments to improve air quality in order to meet the new national standard.

Beginning in 2013, hourly data from 12 monitoring stations have been downloaded in real time from the platform of the Ministry of Environmental Protection of China, and the data are used to analyze the spatial distribution of air pollutants, considering each monitoring station. Under the new national standard, only the background station in Dingling has attained the national standard. Air quality at the urban and suburban stations could not achieve the national standard. Among six pollutants, $\mathrm{PM}_{2.5}$ is the major contributor to the AQI, and the annual average $\mathrm{PM}_{2.5}$ concentration at all stations except the background station exceeds the national standard of $75 \mu \mathrm{g} / \mathrm{m}^{3}$. The rest of the pollutants all achieve the national daily standard (IAQI less than or equal to 100). These results show that, for Beijing, $\mathrm{PM}_{2.5}$ is a major issue to be considered in improving air quality. However, the NAAQS-1996 has not included $\mathrm{PM}_{2.5}$ concentration, making it problematic in evaluating the real air quality in Beijing where $\mathrm{PM}_{2.5}$ is the major contributor to the air quality. The comparison results show that air quality in Beijing is still poor according to NAAQS-2012 with high concentrations of $\mathrm{PM}_{2.5}$, as opposed to the great improvement that was claimed to have been achieved according to results generated by NAAQS-1996. To better understand the long-term air quality variation of Beijing, $\mathrm{PM}_{2.5}$ concentration must be taken into account.

\section{Acknowledgments}

This work was supported in part by the National Natural Science Foundation of China under Grant 41171306, and by the Fundamental Research Funds for the Central Universities under Grant 2014QD02.

\section{Conflicts of Interest}

The authors declare no conflict of interest.

\section{References}

1. Zhang, R.; Jing, J.; Tao, J.; Hsu, S.C.; Wang, G.; Cao, J.; Lee, C.S.L.; Zhu, L.; Chen, Z.; Zhao, Y.; et al. Chemical characterization and source apportionment of $\mathrm{PM}_{2.5}$ in Beijing: Seasonal perspective. Atmos. Chem. Phys. 2013, 13, 7053-7074.

2. Seinfield, J.; Pandis, S. Atmospheric Chemistry and Physics; Wiley \& Sons. Inc.: Hoboken, NJ, USA, 2006. 
3. Bergen, S.; Sheppard, L.; Sampson, P.D.; Kim, S.Y.; Richards, M.; Vedal, S.; Kaufman, J.D.; Szpiro, A.A. A National prediction model for $\mathrm{PM}_{2.5}$ component exposures and measurement error-corrected health effect inference. Environ. Health Persp. 2013, 121, 1017-1025.

4. Janssen, N.A.H.; Fischer, P.; Marra, M.; Ameling, C.; Cassee, F.R. Short-term effects of PM2.5, $\mathrm{PM}_{10}$ and $\mathrm{PM}_{2.5-10}$ on daily mortality in the netherlands. Sci. Total Environ. 2013, 463, 20-26.

5. Krishnan, R.M.; Adar, S.D.; Szpiro, A.A.; Jorgensen, N.W.; Van Hee, V.C.; Barr, R.G.; O’Neill, M.S.; Herrington, D.M.; Polak, J.F.; Kaufman, J.D. Vascular responses to long- and short-term exposure to fine particulate matter mesa air (multi-ethnic study of atherosclerosisi and air pollution). J. Am. Coll. Cardiol. 2012, 60, 2158-2166.

6. Leiva, M.A.; Santibanez, D.A.; Ibarra, S.; Matus, P.; Seguel, R.A. Five-year study of particulate matter $\left(\mathrm{PM}_{2.5}\right)$ and cerebrovascular diseases. Environ. Pollut. 2013, 181, 1-6.

7. Nel, A. Air pollution-related illness: Effects of particles. Science 2005, 308, 804-806.

8. Pope, C.A.; Burnett, R.T.; Thun, M.J.; Calle, E.E.; Krewski, D.; Ito, K.; Thurston, G.D. Lung cancer, cardiopulmonary mortality, and long-term exposure to fine particulate air pollution. Jama-J. Am. Med. Assoc. 2002, 287, 1132-1141.

9. Sarnat, J.A.; Schwartz, J.; Suh, H.H. Fine particulate air pollution and mortality in 20 US cities. $N$. Engl. J. Med. 2001, 344, 1253-1254.

10. Du, X.A.; Kong, Q.A.; Ge, W.H.; Zhang, S.J.; Fu, L.X. Characterization of personal exposure concentration of fine particles for adults and children exposed to high ambient concentrations in Beijing, China. J. Environ. Sci.-China 2010, 22, 1757-1764.

11. Kan, H.D.; London, S.J.; Chen, G.H.; Zhang, Y.H.; Song, G.X.; Zhao, N.Q.; Jiang, L.L.; Chen, B.H. Differentiating the effects of fine and coarse particles on daily mortality in Shanghai, China. Environ. Int. 2007, 33, 376-384.

12. Gavett, S.H.; Koren, H.S. The role of particulate matter in exacerbation of atopic asthma. Int. Arch. Allergy Imm. 2001, 124, 109-112.

13. Guo, Y.M.; Jia, Y.P.; Pan, X.C.; Liu, L.Q.; Wichmann, H.E. The association between fine particulate air pollution and hospital emergency room visits for cardiovascular diseases in Beijing, China. Sci. Total Environ. 2009, 407, 4826-4830.

14. Wang, J.F.; Hu, M.G.; Xu, C.D.; Christakos, G.; Zhao, Y. Estimation of citywide air pollution in Beijing. Plos One 2013, 8, doi:10.1371/journal.pone.0053400.

15. Chan, C.K.; Yao, X. Air pollution in mega cities in China. Atmos. Environ. 2008, 42, 1-42.

16. Chen, W.Y.; Xu, R.N. Clean coal technology development in China. Energy Policy 2010, 38, 2123-2130.

17. Sun, Y.L.; Zhuang, G.S.; Tang, A.H.; Wang, Y.; An, Z.S . Chemical characteristics of PM2.5 and PM10 in haze-fog episodes in Beijing. Environ. Sci. Technol. 2006, 40, 3148-3155.

18. Li, L.J.; Wang, Y.; Zhang, Q.; Li, J.X.; Yang, X.G.; Jin, J. Wheat straw burning and its associated impacts on Beijing air quality. Sci. China Ser. 2008, 51, 403-414.

19. Wang, Q.Q.; Shao, M.; Liu, Y.; William, K.; Paul, G.; Li, X.H.; Liu, Y.A.; Lu, S.H. Impact of biomass burning on urban air quality estimated by organic tracers: Guangzhou and Beijing as cases. Atmos. Environ. 2007, 41, 8380-8390. 
20. Cheng, S.Y.; Lang, J.L.; Zhou, Y.; Han, L.H.; Wang, G.; Chen, D.S. A new monitoring-simulation source apportionment approach for investigating the vehicular emission contribution to the $\mathrm{PM}_{2.5}$ pollution in Beijing, China. Atmos. Environ. 2013, 79, 308-316.

21. Bell, T.L.; Rosenfeld, D.; Kim, K.M.; Yoo, J.M.; Lee, M. I.; Hahnenberger, M. Midweek increase in US summer rain and storm heights suggests air pollution invigorates rainstorms. J. Geophys. Res. Atmos. 2008, 113, D2.

22. Gianicolo, E.A.L.; Serinelli, M.; Cervino, M.; Mangia, C.; Portaluri, M.; Vigotti, M.A. Acute effects of air pollution in brindisi, 2003-2005 is the answer blowing in the wind? Epidemiology 2009, 20, S198-S199.

23. Kim, Y.; Guldmann, J.M. Impact of traffic flows and wind directions on air pollution concentrations in Seoul, Korea. Atmos. Environ. 2011, 45, 2803-2810.

24. Tay, S.S.C. Fires, haze and acid rain: The social and political framework of air pollution in ASEAN and Asia. In Challenges of a Changing Earth; Springer: Berlin, Germany, 2002; pp. 49-55.

25. Walcek, C.J. Effects of wind shear on pollution dispersion. Atmos. Environ. 2002, 36, 511-517.

26. Wang, L.T.; Zhang, P.; Tan, S.B.; Zhao, X.J.; Cheng, D.D.; Wei, W.; Su, J.; Pan, X.M. Assessment of urban air quality in China using air pollution indices (APIs). J. Air Waste Manage. 2013, 63, $170-178$.

27. Guo, Y; Feng, N; Christopher, S.A.; Kang, P; Zhan, F.B.; Hong, S. Satellite remote sensing of fine particulate matter $\left(\mathrm{PM}_{2.5}\right)$ air quality over Beijing using MODIS. Int. J. Remote Sens. 2014, 35, $6522-6544$.

(C) 2015 by the authors; licensee MDPI, Basel, Switzerland. This article is an open access article distributed under the terms and conditions of the Creative Commons Attribution license (http://creativecommons.org/licenses/by/4.0/). 